\title{
Propriedades reológicas sob altas temperaturas de ligantes asfálticos de diferentes fontes modificados com ácido polifosfórico
}

\author{
Thaís Ferreira Pamplona ${ }^{1}$, Fernanda Pilati Sobreiro ${ }^{2}$, \\ Adalberto Leandro Faxina ${ }^{3}$ e Glauco Tulio Pessa Fabbri ${ }^{4}$
}

\begin{abstract}
Resumo: O ácido polifosfórico (PPA) vem sendo utilizado como um aditivo em ligantes asfálticos com o objetivo de enrijecê-los, além de melhorar as propriedades reológicas obtidas sob altas temperaturas sem afetar as propriedades obtidas a baixas temperaturas. O enrijecimento induzido pela adição de PPA é benéfico à resistência à deformação permanente, no entanto, pode ser prejudicial à resistência à fadiga a deformação controlada e às trincas térmicas, já que o revestimento asfáltico torna-se mais quebradiço com o aumento da rigidez. Para avaliar o efeito da adição de PPA em ligantes asfálticos de diferentes fontes, três ligantes asfálticos de penetração 50/70 com diferentes composições químicas e diferentes graus de desempenho (REDUC, LUBNOR E REPLAN) foram modificados com quatro proporções de PPA $(0,5,1,0,1,5$ e 2,0). As amostras foram submetidas ao ensaio de determinação do PG (grau de desempenho) e ao ensaio de fluência e recuperação sob múltiplas tensões (MSCR). Os resultados indicaram que os ligantes asfálticos respondem de maneira diferente à adição de PPA dependendo da sua composição química, sendo o CAP da LUBNOR o que proporciona maiores ganhos com o menor consumo de PPA e o CAP da REDUC o que exige maiores teores de PPA. DOI:10.4237/transportes.v20i4.612.
\end{abstract}

Palavras-chave: ácido polifosfórico, grau de desempenho, MSCR, percentual de recuperação, compliância não-recuperável, ensaios reológicos.

\begin{abstract}
The polyphosphoric acid (PPA) has been used as an additive in asphalt binders in order to stiffen them and also improve the high-temperature rheological properties without affecting the low-temperature properties. The hardening induced by addition of PPA is beneficial to the rutting resistance, however, it can be detrimental to the fatigue and thermal cracking resistances, since the asphalt becomes brittle with the increasing of stiffness. To evaluate the effect of PPA addition in asphalt binders from different sources, three base 50/70 pen-grade asphalt binders with distinct chemical composition and different performance grade (REDUC, LUBNOR AND REPLAN) were modified with five PPA proportions $(0.0,0.5,1.0,1.5$ and $2.0 \%$ ). The specimens were submitted to the PG (penetration grade) and Multiple Stress Creep and Recovery tests. The results indicated that the asphalt binders respond differently to the PPA addition depending on their chemical composition, and the asphalt binder from LUBNOR provides higher gains with the lowest consumption of PPA and the REDUC is the one which requires higher PPA proportions.
\end{abstract}

Keywords: polyphosphoric acid, performance grade, MSCR test, percent recovery, non-recoverable compliance, rheological tests.

\section{INTRODUÇÃO}

A ciência dos ligantes asfálticos para pavimentação tem se desenvolvido, desde o início do século 20 , com base na utilização de ligantes asfálticos puros e, mais tarde, na incorporação de diferentes modificadores como fíleres minerais, asfaltos naturais, óleos aromáticos, ácidos, polímeros e materiais reciclados como a borracha de pneus inservíveis e outros produtos à base de polímeros. O principal objetivo de incorporar modificadores ao ligante asfáltico é gerar um produto mais versátil e mais durável para resistir aos efeitos ambientais e das cargas excessivas do tráfego.

A modificação de ligantes asfálticos com ácido polifosfórico (PPA) não é uma prática recente (Baumgardner et al. 2005; Martin e Baumgardner, 2006). Ligantes asfálticos têm sido modificados com ácido polifosfórico desde a década de 1970, na tentativa de aumentar a viscosidade sem reduzir

\footnotetext{
${ }^{1}$ Thaís Ferreira Pamplona, Departamento de Engenharia de Transportes, Escola de Engenharia de São Carlos, Universidade de São Paulo, São Carlos, SP, Brasil. (e-mail: thaispamplonaa@hotmail.com).

${ }^{2}$ Fernanda Pilati Sobreiro, Departamento Nacional de Infraestrutura de Transportes (DNIT), Brasília, DF, Brasil. (e-mail: fernandapilati@gmail.com).

${ }^{3}$ Adalberto Leandro Faxina, Departamento de Engenharia de Transportes, Escola de Engenharia de São Carlos, Universidade de São Paulo, São Carlos, SP, Brasil. (e-mail: alfaxina@sc.usp.br).

${ }^{4}$ Glauco Tulio Pessa Fabbri, Departamento de Engenharia de Transportes Escola de Engenharia de São Carlos, Universidade de São Paulo, São Carlos, SP, Brasil. (e-mail: glauco@sc.usp.br).
}

Manuscrito recebido em 16/8/2012 e aprovado para publicação em 17/10/2012. Este artigo é parte de TRANSPORTES v. 20, n. 4, 2012. ISSN: 2237-1346 (online). DOI:10.4237/transportes.v20i4.612. substancialmente a penetração e, assim, obter ligantes asfálticos com menor suscetibilidade térmica (Baumgardner, 2012) e maior resistência à deformação permanente sem prejudicar a resistência à formação de trincas de origem térmica. Mais recentemente, o ácido polifosfórico tem sido empregado para ampliar a faixa de temperatura de trabalho dos ligantes asfálticos, isto é, o grau de desempenho segundo a especificação SUPERPAVE (Superior Performing Asphalt Pavements).

Segundo Baumgardner et al. (2005), a adição de ácido polifosfórico pode proporcionar melhoria das propriedades reológicas do ligante asfáltico nas temperaturas altas, sem afetar o PG (Performance Grade ) do material nas temperaturas baixas. Sabe-se que o mecanismo de modificação com o ácido polifosfórico depende das características químicas do ligante asfáltico (Baumgardner et al., 2005; Baumgardner, 2012), logo os benefícios obtidos pela adição do ácido não são os mesmos para todos os tipos de ligante asfáltico. Leite et al. (2004) observaram que a adição de ácido polifosfórico a um resíduo de vácuo permitiu a obtenção de um ligante asfáltico com características superiores ao original e indicaram que a adição de $1,2 \%$ de PPA ao resíduo de vácuo de PG 46-28 foi suficiente para aumentar em dois graus a classificação do material modificado em temperaturas altas (PG 58-22). Martin e Baumgardner (2006) avaliaram o efeito de diferentes teores de ácido $(0,0,0,5$ e 1,0\%) em ligantes asfálticos modificados com $5 \%$ de borracha moída e observaram que a adição de PPA aumenta a viscosidade rotacional a $135^{\circ} \mathrm{C}$ e a recuperação elástica a $25^{\circ} \mathrm{C}$, diminui a separa- 
ção de fase e pode aumentar ou diminuir a rigidez e a taxa de relaxação dependendo do ligante asfáltico de base.

D'Angelo (2012) avaliou o efeito de diferentes teores de ácido polifosfórico em ligantes asfálticos de diferentes fontes e observou que os ligantes asfálticos se comportam de maneira distinta à modificação pelo ácido. A literatura indica que a adição de ácido polifosfórico tem impacto significativamente maior sobre as propriedades reológicas de ligantes asfálticos de natureza predominantemente naftênica (Orange et al., 2004). A suposição de que o ácido polifosfórico dispersa os asfaltenos contribui para explicar o efeito mais intenso do ácido sobre os ligantes asfálticos de natureza naftênica, já que os ligantes asfálticos desta natureza apresentam maior concentração de asfaltenos que os de natureza aromática.

O ácido polifosfórico tem sido defendido pela indústria como um redutor da proporção de polímero, aparentemente com motivações econômicas, já que o custo do ácido é menor que o do polímero. Alguns autores observaram que a adição de uma pequena quantidade de PPA em ligantes asfálticos modificados por polímero reduz a proporção de polímero necessária para atingir um melhor desempenho (Martin e Baumgardner, 2006; Faxina, 2011; Domingos et al., 2011; Arnold et al., 2012; Bernnet, et al., 2012). A redução da porcentagem de polímeros facilita o processamento do ligante asfáltico modificado, diminui sua viscosidade, melhora a trabalhabilidade da mistura asfáltica e aumenta a estabilidade à estocagem do ligante asfáltico modificado.

O ácido polifosfórico parece preservar algumas características esperadas de um ligante asfáltico modificado com uma determinada proporção de polímero mesmo quando esta proporção é reduzida. Bennert et al. (2012) observaram que misturas asfálticas compostas com ligante asfáltico modificado com SBS (estireno-butadieno-estireno) + PPA e compostas com ligante asfáltico modificado apenas com SBS forneceram resistências à fadiga equivalentes. Resistências equivalentes à deformação permanente também foram observadas para estas misturas asfálticas, embora os resultados do ensaio MSCR (Multiple Stress Creep and Recovery) indicassem que o ligante asfáltico modificado apenas com SBS apresentou maior resistência à deformação permanente. Bennert et al. (2012) também constataram que a relação de resistência à tração das misturas compostas com ligante asfáltico modificado com SBS+PPA é maior que a obtida para a mistura composta com ligante asfáltico modificado apenas com SBS, indicando que a primeira mistura apresenta maior resistência ao dano por umidade.

Tendo em vista o efeito diferenciado do ácido polifosfórico sobre ligantes asfálticos com características químicas distintas, este trabalho visa avaliar o efeito de diferentes proporções de PPA $(0,0,0,5,1,0,1,5$ e 2,0\%) em três ligantes asfálticos classificados como penetração 50/70 de diferentes fontes. Os ensaios de determinação do PG e MSCR foram realizados nos ligantes asfálticos puros e modificados para que a comparação entre os ligantes asfálticos pudesse ser realizada e o impacto da modificação com PPA pudesse ser avaliado. A avaliação do impacto da adição de PPA em ligantes asfálticos de diferentes fontes sobre a viscosidade rotacional e a resistência à fadiga dos ligantes asfálticos complementa as análises aqui apresentadas e será publicada oportunamente.

\section{MATERIAIS E MÉTODOS}

\subsection{Materiais}

Três ligantes asfálticos classificados de penetração 50/70 foram utilizados no preparo das amostras modificadas com PPA. Os ligantes asfálticos foram fornecidos por três refinarias da Petrobras: LUBNOR (predominantemente naftênico), REDUC (predominantemente aromático) e REPLAN. O PPA com designação comercial de Innovalt E200, foi fornecido pela Innophos Inc e as proporções utilizadas foram: 0,0, 0,5, 1,0, 1,5 e 2,0.

\subsection{Ensaio de fluência e recuperação sob tensões múltiplas (MSCR)}

O ensaio de fluência e recuperação sob tensões múltiplas substituiu o parâmetro $\mathrm{G}^{*} / \mathrm{sen} \delta$ da especificação Superpave para controle da deformação permanente. $O$ ensaio é realizado utilizando um reômetro de cisalhamento dinâmico, com geometria de placas paralelas de $25 \mathrm{~mm}$ de diâmetro, com distância entre placas de $1 \mathrm{~mm}$, na temperatura determinada pelo grau de desempenho do ligante asfáltico. $\mathrm{O}$ ensaio é feito a tensão controlada de acordo com a norma ASTM D7405-08, na qual a amostra é submetida à tensão constante durante 1 segundo seguido de repouso sob tensão nula por 9 segundos. O protocolo ASTM especifica que dez ciclos de fluência e recuperação sejam aplicados, sem intervalos entre eles, apenas na temperatura do PG do ligante asfáltico, porém, neste trabalho, os ensaios foram realizados nas temperaturas de $52,58,64,70,76,82$ e $88^{\circ} \mathrm{C}$. Nos dez primeiros ciclos de carregamento é aplicada a tensão de 0,1 $\mathrm{kPa}$ e nos dez ciclos seguintes é aplicada a tensão de 3.200 $\mathrm{kPa}$. Para cada ciclo de fluência e recuperação, são registradas as seguintes deformações:

- no início do período de fluência de cada ciclo $\left(\varepsilon_{0}\right)$, no tempo 0 segundo;

- no final do período de fluência de cada ciclo $\left(\varepsilon_{\mathrm{c}}\right)$, no tempo de 1 segundo; e

- no final do período de recuperação de cada ciclo $\left(\varepsilon_{\mathrm{r}}\right)$, no tempo de 10 segundos.

A partir destas medidas, o percentual de recuperação $(\% \mathrm{R})$ e a compliância não-recuperável $\left(\mathrm{J}_{\mathrm{nr}}\right)$ são calculadas por meio das equações 1 e 2 , respectivamente:

$$
\begin{gathered}
\% R(\sigma, N)=\frac{\left[\left(\varepsilon_{c}-\varepsilon 0\right)-\left(\varepsilon_{r}-\varepsilon_{0}\right)\right] \times 100}{\left(\varepsilon_{c}-\varepsilon_{0}\right)} \\
J_{n r}(\sigma, N)=\frac{\left(\varepsilon_{r}-\varepsilon_{c}\right)}{\sigma}
\end{gathered}
$$

em que $\% \mathrm{R}(\sigma, \mathrm{N})$ é o percentual de recuperação e $\mathrm{J}_{\mathrm{nr}}(\sigma, \mathrm{N})$ é a compliância não-recuperável na tensão $\sigma$ (para $\sigma=0,1$ $\mathrm{kPa}$ ou $3,2 \mathrm{kPa}$ ) para o n-ésimo ciclo de fluência e recuperação com n variando de 1 a 10 . Para cada temperatura de ensaio, é obtida a média aritmética dos valore de $\% \mathrm{R}$ e $\mathrm{J}_{\mathrm{nr}}$ nos dez ciclos do ensaio, para cada tensão de cisalhamento.

Uma vez que $\mathrm{J}_{\mathrm{nr}}$ é o parâmetro para altas temperaturas obtido no ensaio MSCR, uma nova especificação foi desenvolvida (Tabela 1), baseada nos valores limites de $\mathrm{J}_{\text {nr }}$ para diferentes níveis de carregamento de tráfego $(\mathrm{S}, \mathrm{H}, \mathrm{V}$ e E), respectivamente designados como padrão (Standard), pesado (Heavy), muito pesado (Very heavy) e extremamente pesado (Extremely heavy) (D’Angelo, 2010). A diferença percentual dos valores de $\mathrm{J}_{\mathrm{nr}}$ a 100 e $3200 \mathrm{~Pa}\left(\mathrm{~J}_{\mathrm{nr} \text {,diff }}\right)$ não deve exceder $75 \%$, a fim de assegurar que o ligante asfáltico não 
Tabela 1. Classificação quanto ao valor de $\mathrm{J}_{\mathrm{nr}}$ (AASHTO M320)

\begin{tabular}{|c|c|c|c|c|}
\hline $\begin{array}{c}\text { Condição de } \\
\text { envelhecimento }\end{array}$ & Propriedade & $\begin{array}{c}\text { Limite máximo } \\
\left(\mathrm{kPa}^{-1}\right)\end{array}$ & Nível de tráfego & $\begin{array}{l}\text { Número de } \\
\text { solicitações }\end{array}$ \\
\hline \multirow{3}{*}{ envelhecido a curto prazo } & \multirow{3}{*}{$\begin{array}{c}\mathrm{J}_{\mathrm{nr}} \text { a } 3.200 \mathrm{~Pa} \mathrm{na} \\
\text { temperatura do } \mathrm{PG}\end{array}$} & 4,0 & padrão $(\mathrm{S})$ & $<10$ milhões \\
\hline & & 1,0 & muito pesado $(\mathrm{V})$ & $>30$ milhões \\
\hline & & 0,5 & extremamente pesado (E) & $>100$ milhões \\
\hline
\end{tabular}

Tabela 2. Valores de percentual de recuperação recomendado pelo FHWA (D’Angelo, 2010)

\begin{tabular}{ll}
\hline $\boldsymbol{J}_{\boldsymbol{n} \boldsymbol{r}} \boldsymbol{a} \mathbf{3 . 2 0 0} \boldsymbol{P a}\left(\mathbf{k P a}^{-1}\right)$ & \%R mínimo \\
\hline $1,01-2,0$ & 30 \\
$0,51-1,0$ & 35 \\
$0,251-0,50$ & 45 \\
$0,125-0,25$ & 50 \\
\hline
\end{tabular}

seja excessivamente sensível à variação no nível de tensão (Anderson et al., 2010; Asphalt Institute, 2010). Valores mínimos do percentual de recuperação também são recomendados e estão indicados na Tabela 2.

\section{APRESENTAÇÃO E ANÁLISE DOS RESULTADOS}

\subsection{Efeito da adição de PPA sobre o PG}

Como indicado na literatura, proporções de ácido de 1,0 até $1,5 \%$ são suficientes para alterar em um ou dois níveis o grau de desempenho do ligante asfáltico em temperaturas altas. Neste sentido, a Figura 1 apresenta uma comparação entre o grau de desempenho contínuo (continuous grade) dos ligantes asfálticos modificados com $1,5 \%$ de PPA e o grau de desempenho contínuo dos ligantes asfálticos de base. O grau de desempenho das amostras foi obtido com base nos valores do parâmetro $\mathrm{G}^{*} / \mathrm{sen} \delta$ das amostras virgens, de acordo com o novo critério da especificação Superpave. A adição de $1,5 \%$ de PPA é suficiente para elevar o PG do CAP LUBNOR de 70 para 88 (3 níveis) e do CAP REPLAN de 64 para $82^{\circ} \mathrm{C}$ (3 níveis), enquanto o PG do CAP REDUC aumentou de 64 para 70 (apenas 1 nível). Estes resultados reforçam o fato de quão dependente é o efeito da adição de PPA da composição química do ligante asfáltico de base. O CAP REDUC se mostrou o menos efetivo à adição de PPA para a proporção de 1,5\%. O CAP LUBNOR atingiu um valor mais alto de PG, pois parte de um PG mais elevado que os outros dois ligantes asfálticos.

A Figura 2 apresenta o grau contínuo dos ligantes asfálti- cos em função da proporção de PPA. É evidente que alguns ligantes asfálticos requerem uma maior proporção de ácido em relação a outros para elevar o grau de desempenho em um, dois ou três níveis. Os ligantes asfálticos da REDUC e da REPLAN apresentaram um grau de desempenho equivalente para baixas proporções de PPA $(0,5 \%$, por exemplo). No entanto, o ligante asfáltico proveniente da LUBNOR apresentou um aumento mais expressivo no grau de desempenho à medida que a proporção de PPA aumentou. Observa-se também uma sensibilidade linear à adição de PPA dos ligantes asfálticos da REPLAN e da LUBNOR.

A quantidade de PPA necessária para elevar a temperatura alta do $\mathrm{PG}$ de cada ligante asfáltico de base em um, dois ou três níveis está mostrada na Tabela 3. Para elevar a temperatura alta do PG em um nível, é necessário adicionar 0,35\% de PPA no CAP da LUBNOR (PG 70 para 76), $0,30 \%$ de PPA no CAP da REDUC (PG 64 para 70) e 0,25\% de PPA no CAP da REPLAN. Para elevar a temperatura alta do $\mathrm{PG}$ em dois níveis é necessário adicionar $1,05,1,55$ e $0,90 \%$ de PPA nos ligantes asfálticos da LUBNOR (PG 70 para 82), da REDUC (PG 64 para 76) e da REPLAN (PG 64 para 76), respectivamente. Para elevar a temperatura alta do $\mathrm{PG}$ em três níveis, as proporções de PPA necessárias seriam de 1,45, 2,00 e 1,40\% para os ligantes asfálticos da LUBNOR (PG 70 para 88), da REDUC (PG 64 para 82) e da REPLAN (PG 64 para 82), respectivamente. O CAP da REPLAN se mostrou o mais sensível à adição de PPA, aumentando a temperatura alta do PG com o menor teor de PPA necessário.

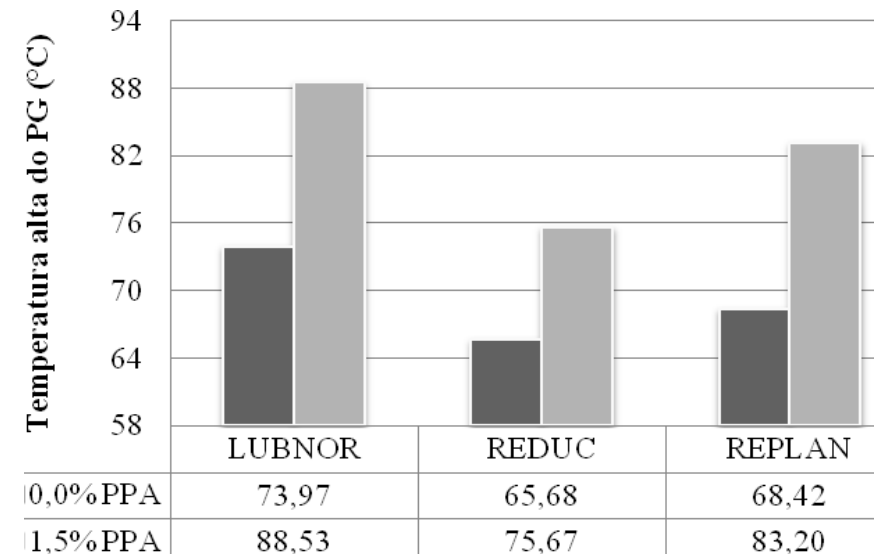

Figura 1. Grau contínuo dos ligantes asfálticos puros e modificados com $1,5 \%$ de PPA 




Figura 2. Grau contínuo dos ligantes asfálticos em função da proporção de PPA

Tabela 3. Quantidade de PPA necessária para aumentar o PG nas temperaturas altas

\begin{tabular}{lllll}
\hline Ligante asfáltico & $\boldsymbol{P G} \mathbf{7 0}$ & $\boldsymbol{P G} \mathbf{7 6}$ & $\boldsymbol{P G} \boldsymbol{8 2}$ & $\boldsymbol{P G} \boldsymbol{8 8}$ \\
\hline LUBNOR & 0,00 & 0,35 & 1,05 & 1,45 \\
REDUC & 0,30 & 1,55 & 2,00 & - \\
REPLAN & 0,25 & 0,90 & 1,40 & - \\
\hline
\end{tabular}

É importante lembrar que o grau de desempenho dos ligantes asfálticos é apenas um critério de classificação baseado no nível de rigidez das amostras nas temperaturas de ocorrência de deformação permanente. Esse critério serve para indicar que os ligantes asfálticos modificados são mais rígidos do que seus ligantes asfálticos de base, mas não pode ser utilizado para classificar ou ordenar diferentes ligantes asfálticos em termos de resistência à deformação permanente. Para isto, o ensaio MSCR deve ser realizado a fim de verificar a real contribuição que o PPA confere aos ligantes asfálticos modificados, em termos de recuperação elástica e deformação não-recuperável.

\subsection{Efeito da adição de PPA sobre as propriedades do ensaio MSCR}

Um questionamento comum feito a respeito da adição do PPA inclui se o PPA tem o mesmo efeito em todos os tipos de ligante asfáltico. As propriedades do ensaio MSCR avaliadas aqui irão mostrar que isto não é verdade. As Figuras 3 e 4 apresentam os percentuais de recuperação dos ligantes asfálticos puros e modificados nos níveis de tensão de $100 \mathrm{e}$ $3200 \mathrm{~Pa}$, respectivamente. As Figuras 5 e 6 apresentam as compliâncias não-recuperáveis dos ligantes asfálticos puros e modificados nos níveis de tensão de 100 e 3200 Pa, res- pectivamente. A primeira impressão obtida dos resultados é de que o efeito da adição de PPA é bastante diferente para cada tipo de ligante asfáltico de base. É importante lembrar que as propriedades do MSCR foram obtidas na temperatura do PG de cada ligante asfáltico. Logo, as propriedades foram medidas a uma temperatura próxima à temperatura na qual os ligantes asfálticos apresentam a mesma rigidez.

A partir da combinação dos resultados do percentual de recuperação e da compliância não-recuperável, pode-se observar a existência de um teor ótimo de PPA para cada ligante asfáltico. $\mathrm{O}$ teor de PPA ótimo para o CAP da REDUC é $1,5 \%$, uma vez que, nesta proporção, o percentual de recuperação a $3200 \mathrm{~Pa}$ foi o mais alto e os valores de compliância não-recuperável nos níveis de tensão de $100 \mathrm{e}$ $3200 \mathrm{~Pa}$ foram os mais baixos. Embora os valores do percentual de recuperação do CAP da REDUC para as concentrações de 1,5 e 2,0\% sejam equivalentes no nível de tensão de $100 \mathrm{~Pa}$, o nível de tensão de $3200 \mathrm{~Pa}$ é mais relevante para o desempenho deste material em relação à deformação permanente. Por esta razão, o resultado obtido a $3200 \mathrm{~Pa}$ foi adotado como referência. $\mathrm{O}$ menor valor de $\mathrm{J}_{\mathrm{nr}}$ indica que $\mathrm{o}$ teor de PPA de 1,5\% torna o CAP da REDUC mais resistente à deformação permanente do que as outras proporções de PPA.

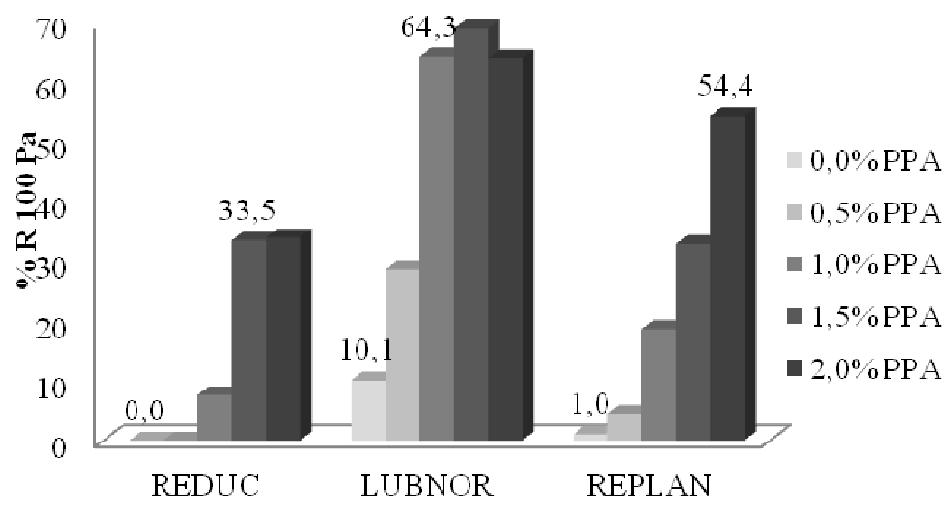

Figura 3. Percentual de recuperação dos ligantes asfálticos puro e modificados, a 100Pa 


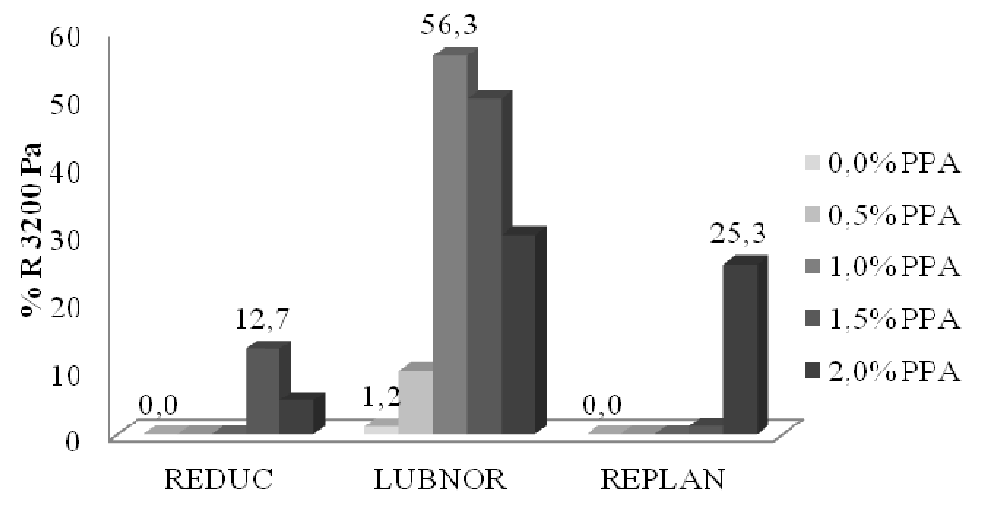

Figura 4. Percentual de recuperação dos ligantes asfálticos puro e modificados, a 3200Pa

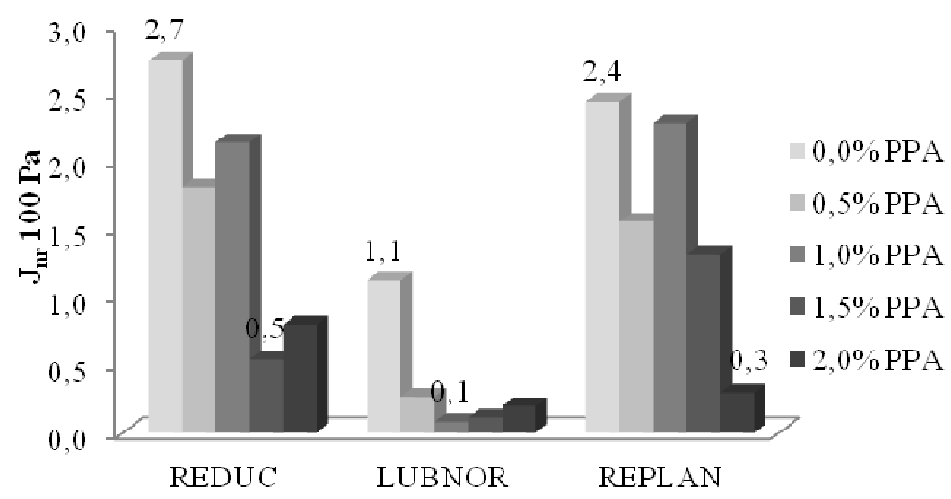

Figura 5. Compliância não-recuperável dos ligantes asfálticos puro e modificados, a 100Pa

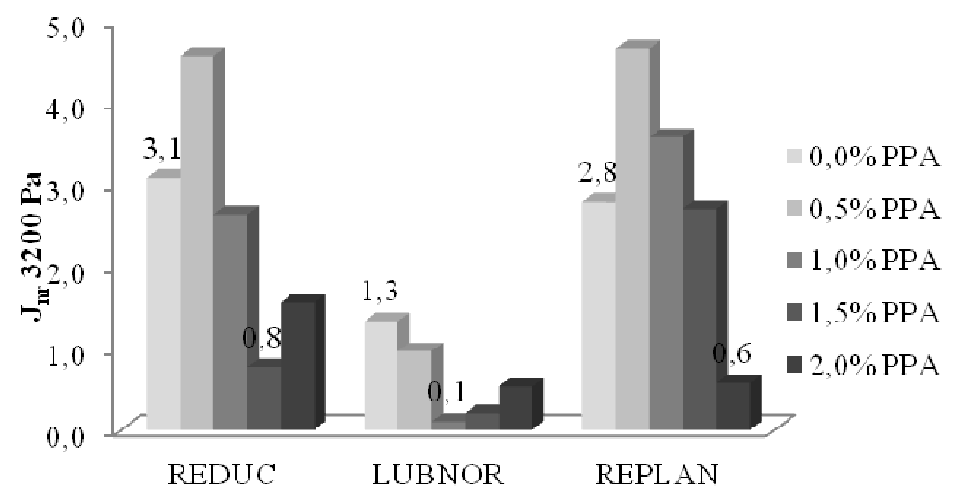

Figura 6. Compliância não-recuperável dos ligantes asfálticos puro e modificados, a 3200Pa

Os teores ótimos de PPA obtidos para os ligantes asfálticos da LUBNOR e da REPLAN são 1,0\% e 2,0\%, respectivamente. O teor ótimo do CAP da LUBNOR foi obtido adotando o mesmo critério relacionado ao percentual de recuperação utilizado na obtenção do teor ótimo do CAP da REDUC, uma vez que o valor do percentual de recuperação a 100 Pa para o CAP da LUBNOR com $1,5 \%$ de PPA é ligeiramente mais elevado do que o valor do percentual de recuperação do CAP da LUBNOR com 1,0\% de PPA. Seria uma tendência natural pensar que a adição de uma proporção de PPA superior a 2,0\% no CAP da REPLAN pudesse gerar melhores resultados em termos das propriedades do MSCR. No entanto, deve-se considerar que o uso de teores de PPA maiores que 2,0\% não são recomendáveis para mo- dificar ligantes asfálticos de penetração 50/70, uma vez que teores altos deste aditivo levam a viscosidades muito altas e que prejudicariam a trabalhabilidade da mistura asfáltica.

$\mathrm{O}$ percentual de recuperação a $100 \mathrm{~Pa}$ do CAP puro da REDUC é de $0,0 \%$, mas a adição de $1,5 \%$ de PPA aumenta este valor em aproximadamente 33 vezes. No mesmo nível de tensão, o valor do percentual de recuperação do CAP puro da LUBNOR é de $10,1 \%$ e a adição de $1,0 \%$ de PPA aumenta em 6 vezes este valor. A adição de $2,0 \%$ de PPA aumenta o percentual de recuperação do CAP puro da REPLAN em aproximadamente 54 vezes. Para o nível de tensão de $3200 \mathrm{~Pa}$, o CAP da LUBNOR é muito mais sensível à adição de PPA do que os ligantes asfálticos da REDUC e da REPLAN. Para o CAP da REDUC, a adição 
Tabela 4. $\mathrm{J}_{\text {nr,diff }}$ dos ligantes asfálticos puros e modificados com o teor ótimo de PPA

\begin{tabular}{ll}
\hline Ligante asfáltico & $\boldsymbol{J}_{\boldsymbol{n}, \text { diff }}(\boldsymbol{\%})$ \\
\hline REDUC 0,0\% PPA & 12,02 \\
REDUC 1,5\% PPA & 41,67 \\
LUBNOR 0,0\% PPA & 18,30 \\
LUBNOR 1,0\% PPA & 25,00 \\
REPLAN 0,0\% PPA & 13,93 \\
REPLAN 2,0\% PPA & 93,22 \\
\hline
\end{tabular}

Tabela 5. Teores mínimos de PPA para obter a compliância não-recuperável máxima de $2 \mathrm{kPa}^{-1}$

\begin{tabular}{llll}
\hline & \multicolumn{3}{l}{ Temperatura $\left({ }^{\circ} \mathrm{C}\right)$} \\
\cline { 2 - 4 } Ligante asfáltico & 70 & 76 & 82 \\
\hline REDUC & 1,15 & 1,50 & 1,95 \\
LUBNOR & 0,00 & 0,25 & - \\
REPLAN & 0,90 & 1,20 & 1,60 \\
\hline
\end{tabular}

Tabela 6. Teores mínimos de PPA para obter a recuperação elástica mínima de $30 \%$

\begin{tabular}{llll}
\hline & \multicolumn{4}{l}{ Temperatura $\left({ }^{\circ} \mathrm{C}\right)$} \\
\cline { 2 - 4 } Ligante asfáltico & 70 & 76 & 82 \\
\hline REDUC & 1,95 & $>2,00$ & $>2,00$ \\
LUBNOR & 0,00 & 0,75 & - \\
REPLAN & 1,40 & 1,75 & $>2,00$ \\
\hline
\end{tabular}

de $1,5 \%$ de PPA aumenta em 13 vezes o percentual de recuperação em relação ao CAP puro da REDUC. Para o CAP da LUBNOR, a adição do teor ótimo aumenta o percentual de recuperação de aproximadamente 47 vezes e, para o CAP da REPLAN, este aumento é de 25 vezes. Pode-se concluir que o CAP da LUBNOR é muito mais sensível à adição de PPA no nível de tensão mais elevado, uma vez que o CAP LUBNOR puro sofreu um maior aumento no percentual de recuperação a $3200 \mathrm{~Pa}$ mesmo com um menor consumo de PPA.

Para o CAP da REDUC, a adição de 1,5\% de PPA diminuiu a compliância não-recuperável em 5 e 4 vezes nos níveis de tensão de 100 e $3200 \mathrm{~Pa}$, respectivamente, em relação ao CAP puro da REDUC. Para o CAP da LUBNOR, a adição do teor ótimo diminuiu o valor de $\mathrm{J}_{\mathrm{nr}}$ em 11 e 13 vezes nos níveis de tensão de 100 e $3200 \mathrm{~Pa}$, respectivamente, e para o REPLAN este decréscimo foi de 8 e 4 vezes. Mais uma vez pode-se concluir que o CAP da LUBNOR é muito mais sensível à adição de PPA nos dois níveis de tensão que os outros dois ligantes asfálticos, uma vez que a adição do seu teor ótimo provocou um decréscimo mais expressivo de $\mathrm{J}_{\mathrm{nr}}$ mesmo com um menor consumo de PPA.

A fim de assegurar que o material não seja tão sensível a alterações no nível de tensão, a relação $\mathrm{J}_{\text {nr,diff }}$ entre os valores de $J_{n r}$ a 100 e $3200 \mathrm{~Pa}$ foi calculada e os resultados obtidos estão apresentados na Tabela 4. São comparados os valores de $\mathrm{J}_{\mathrm{nr} \text {,diff }}$ dos ligantes asfálticos de base com seus respectivos modificados nos teores ótimos de PPA. Conforme recomendação (Anderson et al., 2010; Asphalt Institute, 2010a, 2010b), o valor de $\mathrm{J}_{\text {nr,diff }}$ não deve exceder $75 \%$. Os dados da Tabela 4 mostram que todos os ligantes asfálticos modificados com PPA resultaram mais sensíveis à tensão que os seus respectivos sem PPA. Isto indica que a adição de PPA aumenta a sensibilidade do ligante asfáltico a variações de tensão, tornando-os mais propensos a acumular deformações plásticas. No entanto, levando em consideração o limite de $\mathrm{J}_{\mathrm{nr} \text {,diff }}$ de $75 \%$, o CAP da REPLAN com 2,0\% de PPA é o único que o excede. Em termos práticos, a adição de PPA aumenta a sensibilidade à variação de tensão dos ligantes asfálticos, mas este aumento não é excessivo para os CAPs da LUBNOR e da REDUC, permitindo que estes ligantes asfálticos sejam utilizados com a adição dos seus respectivos teores ótimos de PPA. Em termos de melhor formulação, o ligante asfáltico da LUBNOR é o que possui


nos sensível ao aumento das tensões cisalhantes.

A Tabela 5 apresenta as proporções de PPA mínimas necessárias para atingir o valor máximo de compliância nãorecuperável de $2 \mathrm{kPa}^{-1}$ em cada temperatura. Para obter o valor máximo de $\mathrm{J}_{\mathrm{nr}}$ de $2 \mathrm{kPa}^{-1}$ utilizando o ligante asfáltico proveniente da REDUC, a temperatura alta do pavimento é $82^{\circ} \mathrm{C}$ e a proporção de PPA é de $1,95 \%$. Esta mesma análise não pôde ser realizada para o ligante asfáltico proveniente da LUBNOR uma vez que as amostras com baixa proporção de PPA não foram testadas nas temperaturas mais elevadas (abaixo da temperatura alta do PG). Utilizando o ligante asfáltico da REPLAN, a temperatura alta do pavimento é $88^{\circ} \mathrm{C}$ e a proporção de PPA é aproximadamente $2.00 \%$.

A Tabela 6 apresenta as proporções mínimas de PPA necessárias para obter o valor mínimo de recuperação elástica de $30 \%$ em cada temperatura. Para obter um mínimo de $30 \%$ para o percentual de recuperação utilizando o ligante asfáltico da REDUC, a temperatura mais elevada seria $70^{\circ} \mathrm{C}$ e a proporção de PPA seria 1,95\%. Para temperaturas mais elevadas, proporções de PPA maiores que 2,00\% deveriam ser utilizadas para obter o valor mínimo de $30 \%$ para o percentual de recuperação. Utilizando o CAP da LUBNOR, a temperatura do pavimento mais elevada seria $88^{\circ} \mathrm{C}$ e a proporção de PPA seria 2,00\%. Utilizando o ligante asfáltico da REPLAN, a temperatura do pavimento mais elevada seria $76^{\circ} \mathrm{C}$ e a proporção de PPA seria aproximadamente $1,75 \%$.

\section{CONCLUSÕES}

Este trabalho teve por objetivo avaliar o efeito da adição de ácido polifosfórico em ligantes asfálticos de diferentes fontes. As principais conclusões são: 
- a adição do PPA na faixa de 0,0 até 2,0\% aumentou a temperatura alta do PG das amostras com diferentes intensidades, dependendo do tipo de ligante asfáltico de base; o ligante asfáltico da REPLAN se mostrou o mais sensível à adição de ácido, aumentando a temperatura alta do PG com o menor consumo de PPA;

- para elevar a temperatura alta do PG em um nível, foi necessário adicionar $0,35 \%$ de PPA no CAP da LUBNOR, (PG 70 para 76), 0,30\% de PPA no CAP da REDUC (64 para 70) e $0,25 \%$ de PPA no CAP da REPLAN (64 para 70); para elevar a temperatura alta do PG em dois níveis, foi necessário adicionar $1,05 \%$ de PPA no CAP da LUBNOR, (PG 70 para 82 ), $1,55 \%$ de PPA no CAP da REDUC (64 para 76) e $0,90 \%$ de PPA no CAP da REPLAN (64 para 76); para elevar a temperatura alta do PG em três níveis, foi necessário adicionar $1,45 \%$ de PPA no CAP da LUBNOR, (PG 70 para 88), 2,00\% de PPA no CAP da REDUC (64 para 82) e 1,40\% de PPA no CAP da REPLAN (64 para 82);

- em termos de melhorias provocadas pela adição de PPA, o ligante asfáltico da LUBNOR tem um maior aumento no percentual de recuperação e uma maior redução da compliância não-recuperável em comparação aos outros ligantes asfálticos;

- todos os ligantes asfálticos modificados com os seus respectivos teores ótimos de PPA resultaram mais sensíveis à tensão que os seus respectivos sem PPA;

- levando em consideração o limite de $\mathrm{J}_{\text {nr,diff }}$ de $75 \%$, o CAP da REPLAN com $2,0 \%$ de PPA é o único que o excede e, embora a adição de PPA aumente a sensibilidade à variação de tensão dos ligantes asfálticos, este aumento não é excessivo para os CAPs da LUBNOR e da REDUC, permitindo que estes ligantes asfálticos sejam utilizados com a adição dos seus respectivos teores ótimos de PPA;

- o CAP da LUBNOR é o ligante asfáltico menos sensível ao aumento das tensões cisalhantes, por apresentar o menor $\mathrm{J}_{\text {nr,diff }}$.

Os resultados obtidos neste estudo servem para ilustrar que ligantes asfálticos distintos não se comportam da mesma forma à adição de PPA. As propriedades do MSCR indicaram que existe um teor ótimo de PPA para cada ligante asfáltico de base que proporciona um valor máximo de percentual de recuperação e um valor mínimo de compliância não-recuperável. Estes teores ótimos são: 1,5\% para o CAP da REDUC, $1,0 \%$ para o CAP da LUBNOR e 2,0\% para o CAP da REPLAN, porém, há que se ressaltar que o CAP da REPLAN no seu teor ótimo de PPA apresentou sensibilidade ao aumento do nível de tensão superior ao recomendado.

\section{AGRADECIMENTOS}

Os autores agradecem à Coordenação de Aperfeiçoamento de Pessoal de Nível Superior (CAPES) pela concessão da bolsa de estudos ao primeiro autor e à Fundação de Amparo à Pesquisa do Estado de São Paulo (FAPESP) pela concessão do Auxílio à Pesquisa Jovem Pesquisador (processo FAPESP n ${ }^{\circ}$. 2006/55835-6) ao terceiro autor.

\section{REFERÊNCIAS BIBLIOGRÁFICAS}

Anderson M, J. A. D'Angelo e D. Walker (2010) MSCR: a better tool for characterizing high temperature performance properties. Asphalt, v. 25, n. 2 , p. $15-16,18,21-23$.
Arnold, T. S., J. Youtcheff e S. P. Needham (2012) Use of Phosphoric Acid as Modifier for Hot-Mix Asphalt. Transportation Research Circular E-C160, p. 40-51.

Asphalt Institute (2010) Implementation of the multiple stress creep recovery test and specification. Asphalt Institute Guidance Document.

Asphalt Institute (2010) Guidance on the use of the MSCR test with the AASHTO M320 specification. Asphalt Institute Guidance Document.

Baumgardner, G. L. et al. (2005) Polyphosphoric acid modified asphalt: proposed mechanisms. Journal of the Association of Asphalt Paving Technologists, v. 74, p. 283-305.

Baumgardner, G. L. (2012) Why and How of Polyphosphoric acid Modification. An Industry Perspective. Transportation Research Circular E-C160, p. 14-26.

Bernnet, T. e Martin, J. V. (2012) Polyphosphoric Acid in Combination with Styrene-Butadiene-Styrene Block Copolymer. Transportation Research Circular E-C160, p. 70-85.

D'Angelo J. A. (2012) Effect of Polyphosphoric Acid on Asphalt Binder Properties. Transportation Research Circular E-C160, p. 27-39.

D'Angelo J. A. (2010) The multiple stress creep recovery (MSCR) procedure. Technical Brief prepared by the United States Department of Transportation, Federal Highway Administration.

Domingos, M. D. I., T. F. Pamplona, A. L. Faxina e A. C. Gigante (2011) Viscosidade Rotacional de Ligantes Asfálticos Modificados de Mesmo Grau de Desempenho. Panorama Nacional da Pesquisa em Transportes 2011, ANPET, Belo Horizonte, MG.

Faxina, A. L. (2011) Propriedades reológicas de ligantes asfálticos modificados virgens e envelhecidos a curto prazo. 17 a . Reunião de Pavimentação Urbana, 2011, Porto Alegre, RS.

Leite, L. F. M., C. P. Bittencourt e L. A. H. Nascimento (2004). Efeito do Ácido Polifosfórico no Desempenho dos Ligantes Rodoviários. Panorama Nacional da Pesquisa em Transportes 2004, ANPET, Rio de Janeiro, RJ, v. 1, p. 40-51.

Martin, J. V. e Baumgardner, G. L. (2006) A New Method to Produce Polymer Modified Asphalt with Crumb Rubber and Polyphosphoric Acid: Combining Recycling and Performance, Asphalt Rubber Conference, p. 903-930.

Orange, G.; Dupuis, D.; Martin, J. V. (2004) Chemical Modification of Bitumen throught Polyphosphoric Acid: Properties-microstructure Relationship, 3rd Eurobitume \& Eurasphalt Congress, Viena, Austria, p. 733-745. 